\title{
https://onestopshopfungi.org/, a database to enhance identification of phytopathogenic genera
}

\section{Jayawardena RS ${ }^{1,9}$, McKenzie EHC ${ }^{2}$, Chen $\mathbf{Y J}^{1}$, Phillips AJL ${ }^{3}$, Hongsanan $\mathbf{S}^{4}$, Norphanphoun $\mathbf{C}^{1}$, Abeywikrama $\mathbf{P D}^{1,5}$, Maharachchikumbura $\mathrm{SSN}^{6}$, Manawasinghe IS ${ }^{1,5}$, McTaggart AR ${ }^{7}$, Shivas RG $^{8}$, Gentekaki E', Hyde KD ${ }^{1,10 *}$}

\author{
${ }^{1}$ Center of Excellence in Fungal Research, Mae Fah Luang University, Chiang Rai, Thailand \\ ${ }^{2}$ Landcare Research-Manaaki Whenua, Private Bag 92170, Auckland, NewZealand \\ 3 Faculdade de Ciências, Biosystems and Integrative Sciences Institute (BioISI), Universidade de Lisboa, Campo \\ Grande, 1749-016 Lisbon, Portugal \\ ${ }^{4}$ College of Life Science and Oceanography, Shenzhen University, 1068, Nanhai Avenue, Nanshan, Shenzhen 518055, \\ China \\ 5 Institute of Plant and Environment Protection, Beijing Academy of Agriculture and Forestry Sciences, No.9 of \\ Shuguanghuayuanzhonglu, Haidian District, Beijing 100097, People's Republic of China \\ 6 School of Life Science and Technology, University of Electronic Science and Technology of China, Chengdu 611731, \\ People's Republic of China \\ 7 Queensland Alliance for Agriculture and Food Innovation, The University of Queensland, Brisbane, QLD4001, \\ Australia \\ 8 Centre for Crop Health, University of Southern Queensland, Toowoomba, QLD4350, Australia \\ 9 School of Science, Mae Fah Luang University, Chiang Rai, Thailand \\ 10 Key Laboratory for Plant Diversity and Biogeography of East Asia, Kunming Institute of Botany, Chinese Academy \\ of Sciences, Kunming 650201, People's Republic of China
}

Jayawardena RS, McKenzie EHC, Chen YJ, Phillips AJL, Hongsanan S, Norphanphoun C, Abeywikrama PD, Maharachchikumbura SSN, Manawasinghe IS, McTaggart AR, Shivas RG, Gentekaki E, Hyde KD 2019 - https://onestopshopfungi.org/, a database to enhance identification of phytopathogenic genera. Asian Journal of Mycology 2(1), 281-286, Doi 10.5943/ajom/2/1/18

\begin{abstract}
Correct taxonomic identification of phytopathogens is essential as there is a need to gather precise stored information on different genera. It is important to scientifically document and records the diversity of fungal pathogens in order to collate information, as well as for utilizing the data efficiently. Fungal databases need to play an essential role in the documentation of fungal pathogens. There are numerous fungal databases which provide lists of fungal names, literature, DNA sequence and morphological data to facilitate morpho-molecular identification, however, few are dedicated to the identification of phytopathogens. For this reason, a web-based platform is established, namely https://www.onestopshopfungi.org to fill the void, as well to enhance the identification of phytopathogenic genera based on the One Stop Shop publication series. This paper introduces the database, explains its function, provides data on the information it includes and how to use it and invites plant pathologists to participate in building the database.
\end{abstract}

Keywords - One stop shop - Molecular phylogeny - Symptoms - Plant pathogens

\section{Introduction}

Fungi have their own unique cell biology and life cycle and also play critical roles in wider 
eco-systems. They may show endophytism, parasitism, saprotrophism and symbiosis with plants (Zeilinger et al. 2015, Jayawardena et al. 2018). Fungi are the main disease-causing agent of plants, resulting in a significant economic loss by reducing the quantity and quality of crops (Almeida et al. 2019, Chethana et al. 2019). Many phytopathogenic fungi and related organisms have been studied over the decades to clarify their systematics and biology, and to search for measures to control their activities (Hyde et al. 2014, Jayawardena et al. 2019a, b). However, due to taxonomic inconsistencies, correct identification of these pathogens has not been an easy task. Most of the biotrophic pathogens cannot be cultured away from their host plants as they grow within the living plant cells and many plant pathogenic fungi fail to produce sexual morphs in laboratory conditions resulting in a poor understanding of the biology of phytopathogenic fungi (Hyde et al. 2018a). The emergence of the increased use of DNA sequence data for characterization has provided a better understanding of the systematics of phytopathogenic fungi (Nilsson et al. 2014). DNA sequence analyses have helped to identify many paraphyletic groups and species complexes among phytopathogens (Hyde et al. 2014). Correct identification of phytopathogens is essential in establishing disease management strategies and in global plant trade. Therefore, unravelling taxonomic confusion to enable correct identification is very important. Furthermore, there is a need to re-evaluate the old names that were introduced based on morphology alone (Cai et al. 2011, Ko et al. 2011, Hyde et al. 2018b).

One Stop Shop (OSS) is a series of papers focused on providing a stable platform for the taxonomy of plant pathogenic fungi and related organisms (Hyde et al. 2014, Jayawardena et al. 2019a, b). Genera included in this series of publications are associated with plant disease. However, some may not be well-known plant pathogens and Kochs' postulates may not have established to prove their pathogenicity. This series of papers seeks to facilitate present and future studies of phytopathogenic fungi and related organisms by providing a phylogenetic backbone tree as well as summarizing the disease symptoms, hosts and geographical distribution. Our motivation is to combine all recent molecular data, recommendations on correct names, type material, geo/ecological observations and literature into a comprehensive, uniform treatise.

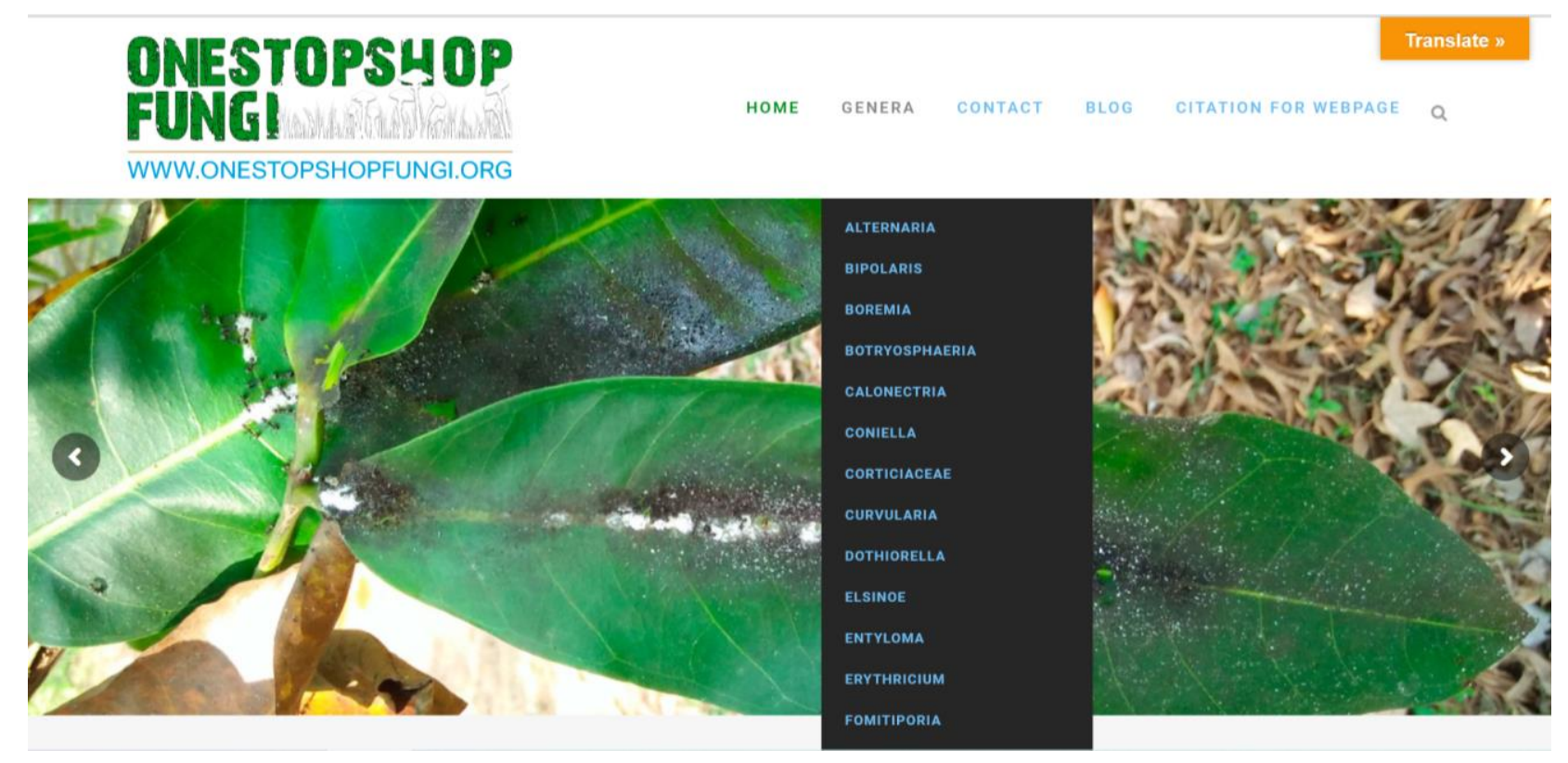

Fig. 1 - Home page of OSS database with genera search.

\section{The need for a comprehensive database for phytopathogens in a phylogenetic framework}

The last two decades have witnessed the emergence of DNA sequence data as a valuable tool that has revolutionized mycology (Nilsson et al. 2014). Combining DNA sequence data of phytopathogenic genera with morphological characters in the early 1990s resulted in a deeper 
understanding concerning the ecology, distribution and systematics of phytopathogenic genera (Hyde et al. 2014).

It is important to scientifically document and records fungal diversity to preserve, as well as use it efficiently (Jayawardena et al. 2016). Databases play an important role in aggregating the scattered data into an easily accessible form. It is the responsibility of plant pathologists and mycologists to ensure that data and results are available for the end-users (Jayasiri et al. 2015). Even though there are numerous fungal databases providing lists of names of fungi, literature, DNA sequences and morpho-molecular identification, very few are dedicated to the identification of phytopathogens. For this reason, a web-based platform was established, namely https://onestopshopfungi.org/ (Fig. 1), to fill the void.

\section{One stop shop (OSS) database}

Current taxonomy and concepts of fungal classification have undergone a rapid transition. In this context, establishing an expert database is essential for the management and distribution of taxonomic data. With the new insights provided by molecular data on phytopathogenic genera, OSS will inevitably be a critical resource for accurate identification of pathogens for disease management. The concept behind this database is to provide a platform and a more structured approach for plant pathologists to understand taxonomy and phylogeny. This fungal database allows mycologists to understand disease symptoms, host distribution, classification and morphology, and provides an updated phylogeny, which will enhance current understanding of plant pathogens and give better insights into the current fungal classification system. This platform is user-friendly and anyone can easily search and browse for phytopathogenic genera and retrieve the relevant information.

\section{Construction}

All phytopathogenic genera in OSS are listed according to the most recent classifications. The database includes symptoms, photographic plates, notes, phylogenetic trees of each genus and other important data such as host range and distribution, related to each phytopathogenic genus.

\section{Database interface and visualization}

OSS database provides insights into an updated classification of phytopathogens based on morphological and molecular data. The interface is user-friendly and easy to work with. Dropdown menu 'Genera' (Fig. 1) takes you to a separate page for each genus. A click on a genus name reveals data on a particular genus (Fig. 2). Within, each genus, background, classification, disease symptoms, morphological based identification and recommended genetic markers are provided. A phylogenetic tree for identification of species in a genus is usually provided (Fig. 3). Photographic plates of morphology and disease symptoms are provided when available (Fig. 2). On the left-hand side of the page, under 'Categories', all genera are listed to provide quick access for the user to transfer between interesting genera (Fig. 4). In the home page, the latest posts are shown for ease of access. Upon clicking the figures in each entry, a new window will open, for ease of viewing the details. As the database develops, it will include all groups of true phytopathogenic fungi and fungi-like organisms and will be continually updated. We have invited international curators with expertise in plant pathology to monitor the web page and continuously suggest improvements (Table 1). Other interested parties can contact the moderator and offer suggestions, or their services as curators.

\section{Acknowledgements}

This work was financed by the Mushroom Research Foundation (MRF), Thailand. Alan JL Phillips acknowledges the support from UID/MULTI/04046/2019 Research Unit grant from FCT, Portugal to BioISI. 


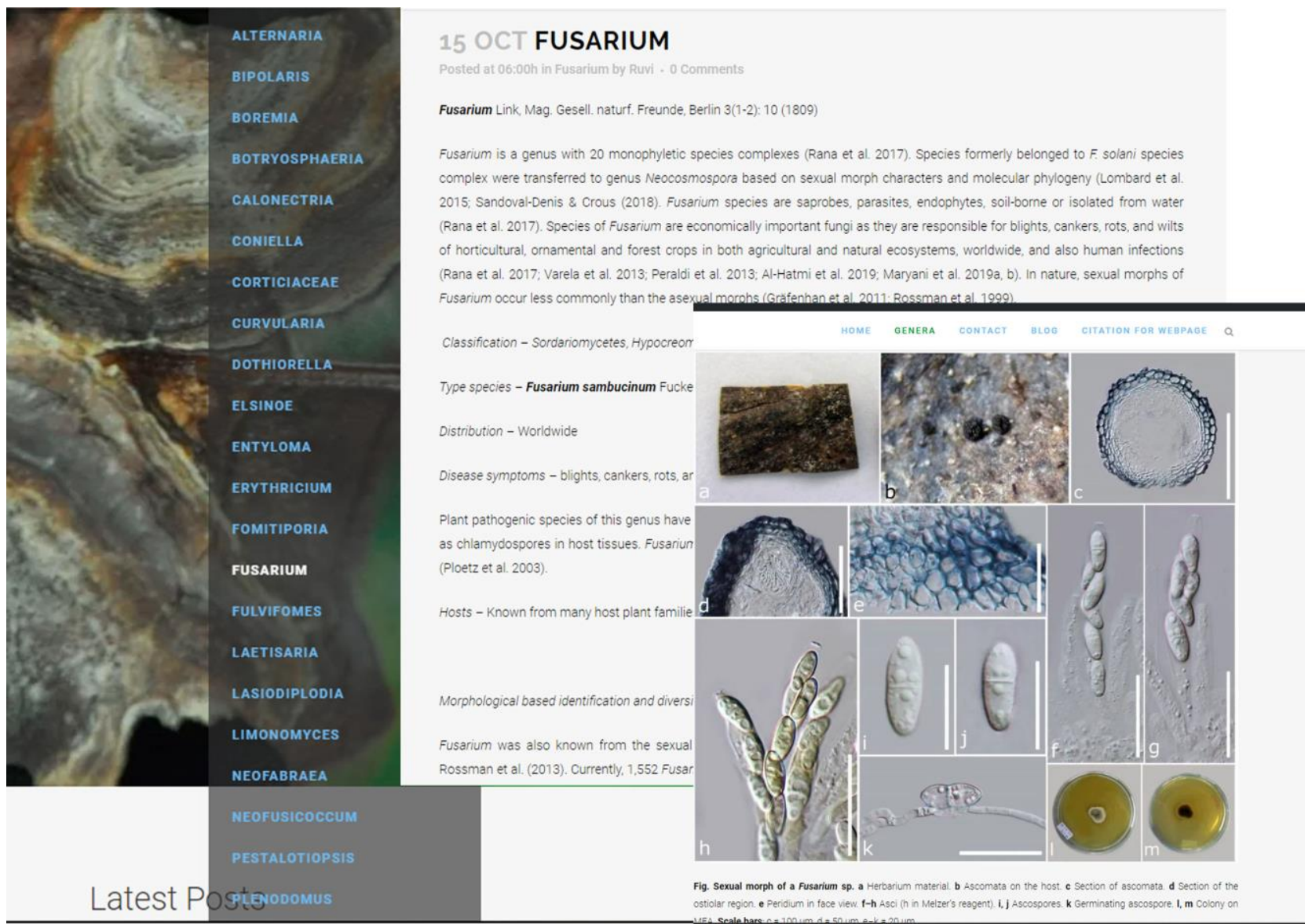

Fig. 2 - Details on the genus Fusarium with description and plate of typical species.

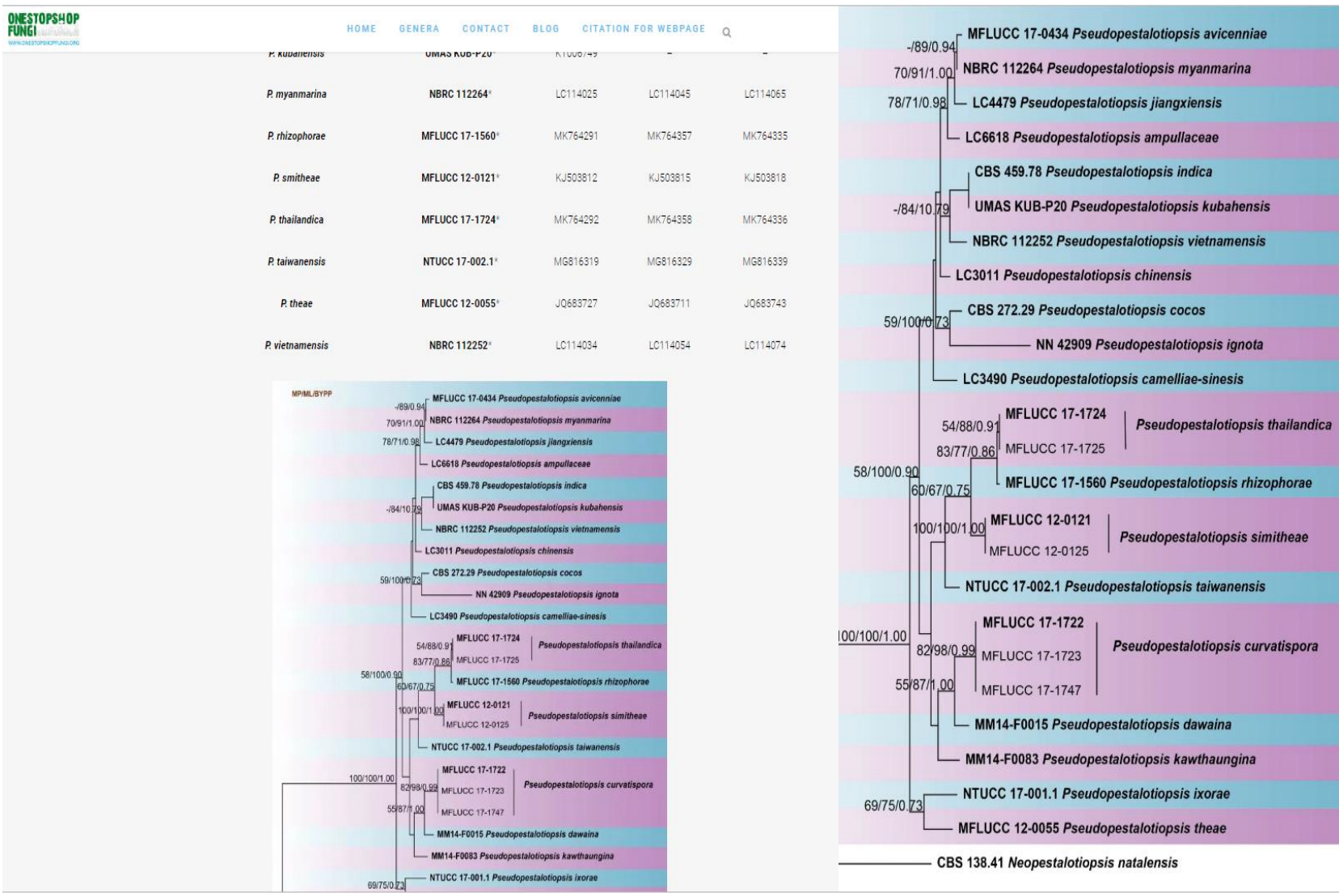

Fig. 3 - Phylogenetic tree for identification of species in Pesudopestalotiopsis 


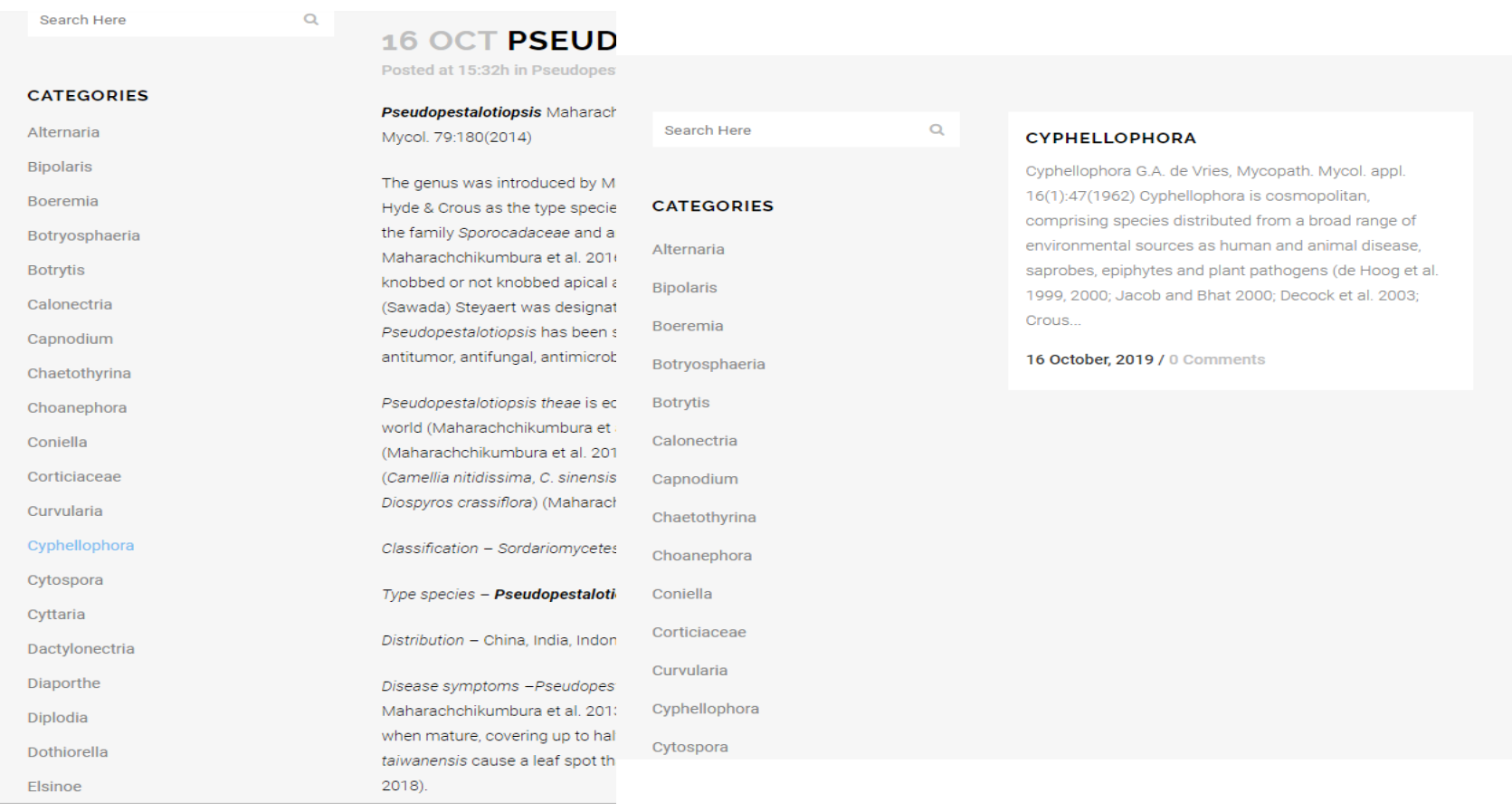

Fig. 4 - 'Categories' option to easily switch between genera.

Table 1 Fungal groups and expert curators

\begin{tabular}{|l|l|}
\hline Fungal Group & Expert curators \\
\hline Ascomycota & Kevin D. Hyde \\
& Eric H. C. McKenzie \\
& Ruvishika S. Jayawardena \\
& Yi-Jyun Chen \\
\hline Dothideomycetes & $\begin{array}{l}\text { Alan J.L. Phillips } \\
\text { Sinang Hongsanan }\end{array}$ \\
\hline Sordariomycetes & $\begin{array}{l}\text { Chada Norphanphoun } \\
\text { Pranami Abeywickrama } \\
\text { Sajeewa S. N. Maharachchikumbura }\end{array}$ \\
\hline Fungus-like organisms & Ishara S. Manawasinghe \\
\hline Rusts and smuts & Alistair R. McTaggart \\
& Roger G. Shivas \\
\hline Basal fungi & Eleni Gentekaki \\
\hline
\end{tabular}

\section{References}

Almeida F, Rodrigues ML, Coelho C. 2019 - The still underestimated problem of fungal diseases worldwide. Frontiers in microbiology 10, article 214.

Cai L, Udayanga D, Manamgoda DS, Maharachchikumbura SS et al. 2011 - The need to carry out re-inventory of plant pathogenic fungi. Tropical Plant Pathology 36, 205-213.

Chethana KWT, Jayawardena RS, Zhang W, Zhou YY et al. 2019 - Molecular characterization and pathogenicity of fungal taxa associated with cherry leaf spot disease. Mycosphere 10, 490530.

Hyde KD, Nilsson RH, Alias SA, Ariyawansa HA et al. 2014 - One stop shop: backbones tree for important phytopathogenic genera: I. Fungal Diversity 67, 21-125.

Hyde KD, Al-Hatmi AMS, Andersen B, Boekhout T et al. 2018a - The worlds' ten most feared fungi. Fungal Diversity 93, 161-194.

Hyde KD, Norphanphoun C, Chen J, Dissanayake AJ et al. 2018b - Thailand's amazing diversity: up to $96 \%$ of fungi in northern Thailand may be novel. Fungal Diversity 93, 215-239. 
Jayasiri SC, Hyde KD, Ariyawansa HA, Bhat J et al. 2015 - The Faces of Fungi database: fungal names linked with morphology, phylogeny and human impacts. Fungal Diversity 74, 3-18.

Jayawardena RS, Hyde KD, Jeewon R, Li XH et al. 2016 - Mycosphere Essay 6: Why is it important to correctly name Colletotrichum species? Mycosphere 7, 1076-1092.

Jayawardena RS, Purahong W, Zhang W, Wubet T et al. 2018 - Biodiversity of fungi on Vitis vinifera L. revealed by traditional and high-resolution culture-independent approaches. Fungal Diversity 90, 1-84.

Jayawardena RS, Hyde KD, Jeewon R, Ghobad-Nejhad et al. 2019a - One stop shop II: taxonomic update with molecular phylogeny for important phytopathogenic genera: 26-50 (2019). Fungal Diversity 94, 41-129.

Jayawardena RS, Hyde KD, McKenzie EHC, Jeewon R et al. 2019b - One stop shop III: taxonomic update with molecular phylogeny for important phytopathogenic genera: 51-75 (2019). Fungal Diversity 98, 77-160.

Ko TWK, McKenzie EHC, Bahkali AH, To-Anun C et al. 2011 - The need for re-inventory of Thai phytopathogens. Chiang Mai Journal of Science, 38, 625-637.

Nilsson RH, Hyde KD, Pawlowska J, Ryberg M et al. 2014 - Improving ITS sequence data for identification of plant pathogenic fungi. Fungal Diversity 67, 11-19.

Zeilinger S, Gupta VK, Dahms TE, Silva RN et al. 2015 - Friends or foes? Emerging insights from fungal interactions with plants. FEMS microbiology reviews 40, 182-207. 